\title{
Asia Pacific Stroke Conference 2020: Bringing Innovation to Stroke Care in Asia Pacific Countries
}

\author{
Kay Sin Tan ${ }^{a}$ Sun U Kwon ${ }^{b}$ Keun Hwa Jung ${ }^{c}$ Joung Ho Rha ${ }^{d}$ \\ Byung Woo Yoon ${ }^{\mathrm{C}}$ Narayanaswamy Venketasubramanian ${ }^{\mathrm{e}}$ \\ ${ }^{a}$ Division of Neurology, Department of Medicine, University of Malaya, Kuala Lumpur, Malaysia; ${ }^{b}$ Department of \\ Neurology, Asan Medical Center, University of Ulsan College of Medicine, Seoul, South Korea; ' $D e p a r t m e n t ~ o f$ \\ Neurology, Seoul National University Hospital, Seoul, South Korea; ${ }^{d}$ Department of Neurology, Inha University \\ College of Medicine, Incheon, South Korea; ${ }^{e}$ Raffles Neuroscience Centre, Raffles Hospital, Singapore, Singapore
}

The Asia Pacific is a diverse area with many varying levels of resources within its stroke care systems. The Asia Pacific Stroke Organisation (APSO) [1] was founded in 2009 and organised its first annual flagship conference, the Asia Pacific Stroke Conference (APSC), in Colombo, Sri Lanka in 2011. Since then, this conference has been rotated across many cities in the region.

In recent years, the practice of stroke neurology has changed worldwide, with many centres adopting the latest advances, which have been adapted to existing systems along with the many challenges that emerge. As a result, each country has its own narrative, conveniently brought together in the formative context of this conference series.

The year 2020 is special because it is the 12 th year since the inception of the APSO and the year of the 10th APSC. With the difficulties brought by the COVID-19 pandemic globally, the APSC has been reformatted for the first time into a virtual edition. The host, the Korean Stroke Society together with the International Scientific Committee, worked very hard to prepare a detailed scientific program that included many accomplished speakers and experts from the region and beyond. As in the physical

karger@karger.com

(c) 2020 S. Karger AG, Basel

www.karger.com/ced

Karger'? meetings, there are virtual workshops and symposia covering systems of care, endovascular thrombectomy, intravenous thrombolysis, neurosonology, novel anticoagulants, and vascular cognitive impairment.

As in previous conferences [2], this meeting also received representative work from across the region with more than 120 abstract submissions. The content of the posters that have been submitted reflect the entirety of stroke care, including hyperacute management, epidemiology, risk factors, prevention, neurosonology and neuroimaging, as well as rehabilitation and restorative therapies. The impact of COVID-19 on stroke care was among the main contemporary issues.

The other highlights (presented in the Emerging Scholar's and Late Breaking sessions) include wearable devices and stroke prediction, use of artificial intelligence and neural networks in the prediction of intracerebral haemorrhage post thrombolysis, stroke subtypes in special populations from the Japanese Stroke Databank, metabolic influence on leptomeningeal collaterals in acute stroke, the impact of sleep apnoea on cerebral microvasculature, the impact of ethnicity on $\mathrm{T}_{\max }$ thresholds, and the use of non-invasive brain stimula- 
tion in stroke recovery. The best abstracts will receive awards in recognition for their outstanding quality, with special emphasis on submissions from low- and low-middle income countries. More importantly, the participants will have the ability to interact in real time with the authors through electronic media during the conference, ensuring maximum exposure of the submitted work. To date, there are 400 registered participants from 20 countries.

The APSO has been investing time and resources into stroke education as one of our key thrusts. In addition to the annual APSCs, there is available funding for member societies to organise local educational meetings and grants for visiting APSO professorships to allow expertise from or outside the region to contribute to these regional meetings. We have also announced financial support for short training fellowships to stroke centres of excellence. Stroke guidelines of member countries are accessible via our website [2]. Our website also has links to the webpages of member societies as well as to stroke support groups in the region, which we hope will be a valuable resource for stroke survivors and families. Abstracts of previous APSCs have been put together and can easily be retrieved via our website. In this regard, our relationship with Cerebrovascular Diseases and Karger over the last decade is deeply valued.

The next APSC will be held in India in December 2021. We are looking forward to another exciting meeting and welcome all to attend.

\section{Acknowledgment}

The authors would like to thank all the member countries of the APSO, the members of the organising committee and scientific committee for the 2020 edition of the APSC, as well as all the speakers, sponsors, and participants for their support in this meeting during these unprecedented times.

\section{Conflict of Interest Statement}

The authors have no conflicts of interest to declare.

\section{Funding Sources}

No funding sources were required for this article.

\section{Author Contributions}

K.S. Tan wrote the first draft. It was reviewed and amended critically for content and clarity by all the listed co-authors. The final draft was approved by all authors.

\section{References}

1 Venketasubramanian N, Anderson C, Mehndiratta M, Lin RT, Tan KS, Huang CY. Organizational Update: Asia Pacific Stroke Organization. Stroke. 2017 Sep;48(9):e252-4.

2 Asia Pacific Stroke Organisation. Education. https://www.theapso.com/ education. 